\title{
Insulin counteracts glucotoxic effects by suppressing thioredoxin-interacting protein production in INS-1E beta cells and in Psammomys obesus pancreatic islets
}

\author{
M. Shaked • M. Ketzinel-Gilad • Y. Ariav • E. Cerasi • \\ N. Kaiser • G. Leibowitz
}

Received: 22 September 2008 / Accepted: 12 January 2009 / Published online: 13 February 2009

(C) Springer-Verlag 2009

\begin{abstract}
Aims/hypothesis In type 2 diabetes, glucose toxicity leads to beta cell apoptosis with decreased beta cell mass as a consequence. Thioredoxin-interacting protein (TXNIP) is a critical mediator of glucose-induced beta cell apoptosis. Since hyperglycaemia leads to elevated serum insulin, we hypothesised that insulin is involved in the regulation of TXNIP protein levels in beta cells.

Methods We studied the production of TXNIP in INS-1E beta cells and in islets of Psammomys obesus, an animal model of type 2 diabetes, in response to glucose and different modulators of insulin secretion.

Results TXNIP production was markedly augmented in islets from diabetic P. obesus and in beta cells exposed to high glucose concentration. In contrast, adding insulin to the culture medium or stimulating insulin secretion with different secretagogues suppressed TXNIP. Inhibition of glucose and fatty acid-stimulated insulin secretion with diazoxide increased TXNIP production in beta cells. Nitric oxide (NO), a repressor of TXNIP, enhanced insulin signal transduction, whereas inhibition of NO synthase abolished its activation, suggesting that TXNIP inhibition by NO is mediated by stimulation of insulin signalling. Treatment of
\end{abstract}

Electronic supplementary material The online version of this article (doi:10.1007/s00125-009-1274-2) contains supplementary material, which is available to authorised users.

M. Shaked · M. Ketzinel-Gilad · Y. Ariav · E. Cerasi · N. Kaiser · G. Leibowitz $(\bowtie)$

Endocrinology and Metabolism Service, Department of Medicine, Hadassah, Hebrew University Medical Center,

P.O. Box 12000, Jerusalem 91120, Israel

e-mail: gleib@hadassah.org.il beta cells chronically exposed to high glucose with insulin reduced beta cell apoptosis. Txnip knockdown mimicking the effect of insulin prevented glucose-induced beta cell apoptosis.

Conclusions/interpretation Insulin is a potent repressor of TXNIP, operating a negative feedback loop that restrains the stimulation of TXNIP by chronic hyperglycaemia. Repression of TXNIP by insulin is probably an important compensatory mechanism protecting beta cells from oxidative damage and apoptosis in type 2 diabetes.

Keywords Apoptosis $\cdot$ Beta cells $\cdot$ Insulin $\cdot$ Oxidative stress $\cdot$ Thioredoxin $\cdot$ Thioredoxin-interacting protein . Type 2 diabetes

$\begin{array}{ll}\text { Abbreviations } \\ \text { EGFP } & \text { Enhanced green fluorescent protein } \\ \text { GLP-1 } & \text { Glucagon-like peptide 1 } \\ \text { GSNO } & \text { S-Nitroso-glutathione } \\ \text { IBMX } & \text { 3-Isobutyl-1-methylxanthine } \\ \text { L-NAME } & \text { L-NG-nitro-L-arginine methyl ester } \\ \text { NO } & \text { Nitric oxide } \\ \text { PI3 kinase } & \text { Phosphoinositide 3-kinase } \\ \text { PKB } & \text { Protein kinase B } \\ \text { TXNIP } & \text { Thioredoxin-interacting protein }\end{array}$

\section{Introduction}

In type 2 diabetes mellitus, elevated blood glucose concentration induces beta cell dysfunction and apoptosis, leading to exacerbation of hyperglycaemia, a process called glucotoxicity $[1,2]$. The mechanisms underlying the 
deleterious effects of glucose on beta cell function and survival are not entirely clear but are thought to involve oxidative stress induced by increased nutrient flux, leading to excessive generation of free radicals $[3,4]$. The balance between free radical generation and the capacity of antioxidants to scavenge them determines the degree of oxidative stress exerted on the beta cells. Thioredoxin is a ubiquitous oxireductase that is abundant in pancreatic beta cells [5]. Thioredoxin partners with thioredoxin reductase and thioredoxin peroxidase to reduce oxidised proteins and scavenge free radicals [6]. In addition to its antioxidative function, thioredoxin mediates antiapoptotic effects through interaction with signalling molecules and transcription factors, such as redox effector protein-1 (Ref-1), nuclear factor $\mathrm{kB}(\mathrm{NF}-\mathrm{kB})$ and apoptosis signal regulating kinase-1 (ASK-1) [6].

Thioredoxin-interacting protein (TXNIP), also known as vitamin D3 upregulated protein-1 (VDUP-1) and thioredoxin binding protein-2 (TBP-2), is an endogenous inhibitor of thioredoxin which, by binding to its redox-active cysteine residues, inhibits the antioxidative function of thioredoxin [7]. Of major importance is the observation that TXNIP production is robustly induced by glucose in islets as well as other tissues [8-11]. Glucose regulates TXNIP mainly at the level of transcription, and promoter analysis of the human TXNIP gene identified a distinct carbohydrate response element consisting of a non-palindromic repeat of two E-boxes conferring glucose responsiveness [12]. As would be expected, induction of TXNIP by glucose was shown to promote oxidative stress and apoptosis in vascular smooth muscle cells and in the INS-1 beta cell line $[9,12]$. Moreover, islets from Txnip mutant mice are protected from glucose-induced apoptosis [13, 14]. Thus, TXNIP is emerging as an important mediator of beta cell glucotoxicity.

Physiological mechanisms that counteract the induction of TXNIP by glucose may restrain the stress exerted on beta cells and improve their survival in type 2 diabetes. Chronic hyperglycaemia leads to persistent elevation of the serum insulin concentration. Insulin inhibits TXNIP expression in human skeletal muscle [15]; however, the effect of secreted insulin on TXNIP expression in beta cells has not been reported. Therefore, the effects of insulin secretagogues and insulin itself on TXNIP levels were studied in INS-1E beta cells and in islets of Psammomys obesus, an animal model of type 2 diabetes.

\section{Methods}

Islet isolation and INS-1E beta cell line culture Diabetesprone male P. obesus (Hebrew University Colony, Harlan, Jerusalem, Israel), aged 2.5-3.5 months, were fed a low- energy $(9.96 \mathrm{~kJ} / \mathrm{g})$ diet (Koffolk, Petach-Tikva, Israel), which maintains normoglycaemia $(3-5 \mathrm{mmol} / \mathrm{l}$ in this species). Diabetes, defined by random blood glucose levels $>8.3 \mathrm{mmol} / \mathrm{l}$, was induced by feeding a high-energy diet (14.23 kJ/g; Teklad Global Diets, Boston, MA, USA) [16]. Islets were isolated from normoglycaemic and diabetic P. obesus by collagenase digestion (Collagenase P; Roche Diagnostics, Mannheim, Germany) as described [17]. The islets were used after repeated washes with Hanks' balanced salt solution. They were cultured in suspension in RPMI 1640 medium (Biological Industries, Beit-Haemek, Israel) with $10 \%$ fetal bovine serum, $100 \mathrm{U} / \mathrm{ml}$ penicillin, $100 \mu \mathrm{g} / \mathrm{ml}$ streptomycin, $2 \mathrm{mmol} / \mathrm{l}$ L-glutamine (Biological Industries) and different glucose concentrations. Animal use was approved by the Institutional Animal Care and Use Committee of the Hebrew University and the Hadassah Medical Organization.

INS-1E cells were grown in RPMI 1640 medium containing different glucose concentrations as indicated, supplemented with $10 \%$ fetal bovine serum, $100 \mathrm{U} / \mathrm{ml}$ penicillin, $100 \mu \mathrm{g} / \mathrm{ml}$ streptomycin, $1 \mathrm{mmol} / \mathrm{l}$ sodium pyruvate, $2 \mathrm{mmol} / \mathrm{l} \mathrm{L}$-glutamine, $10 \mathrm{mmol} / 1$ HEPES and $50 \mathrm{nmol} / 1$ 2-mercaptoethanol.

Experimental procedure Islets from $P$. obesus were incubated overnight with medium containing 3.3 or $22.2 \mathrm{mmol} / \mathrm{l}$ glucose with and without $250 \mu \mathrm{mol} / 1 \mathrm{diaz}-$ oxide. INS-1E cells were incubated overnight with $3.3 \mathrm{mmol} / 1$ glucose, then transferred for $2 \mathrm{~h}$ to medium containing 11.1 and $22.2 \mathrm{mmol} / \mathrm{l}$ glucose with and without $500 \mathrm{nmol} / 1$ human insulin (Humulin R; Eli Lilly, Fegersheim, France) or the insulin secretagogues $\mathrm{KCl}$ (40 mmol/1), 3-isobutyl-1-methylxanthine (IBMX; $0.5 \mathrm{mmol} / \mathrm{l})$, exendin $4(100 \mathrm{nmol} / \mathrm{l}$; Bachem, Torrance, CA, USA) and palmitate $(0.5 \mathrm{mmol} / \mathrm{l})$. In experiments on the effect of secreted insulin on TXNIP protein levels, INS$1 \mathrm{E}$ cells were treated with different insulin secretagogues and palmitate with and without diazoxide or $20 \mu \mathrm{mol} / \mathrm{l}$ of the phosphoinositide 3-kinase (PI3 kinase) inhibitor LY294002.

The role of nitric oxide (NO) in the regulation of insulin signalling and TXNIP levels was studied using the NO donor $S$-nitroso-glutathione (GSNO) and the NO synthase inhibitor L-NG-nitro-L-arginine methyl ester (L-NAME).

Islet and INS-1E cell extracts were used for quantitative real-time PCR and western blot analyses. Medium was collected for insulin measurement by RIA. All reagents except for insulin and exendin 4 were purchased from Sigma (Rehovot, Israel).

Vector design and virus production The small interfering RNA (siRNA) sequence targeted against Txnip corresponded 
to bases 864-886 of the mRNA (accession number NM_001008767). It was generated by annealing of the sense and antisense oligonucleotides: 5'-CGATCTGAGTGAG CACTTTGGTCTGGCTTTCAAGAGAAGCCAG ACCAAAGTGCTCACTCAGTTTTTGAT and 5'ATCAAAAACTGAGTGAGCACTTTGGTCTGGCTTCTC TTGAAAGCCAGACCAAAGTGCTCACTCAGAT (the Txnip siRNA sequences are underlined).

The annealed oligonucleotides were inserted into the plasmid pBS-H1 digested with ClaI and EcoRV downstream to the human $\mathrm{H} 1$ promoter to produce the plasmid pBS-H1-shRNA.TXNIP. The Txnip silencing cassette was introduced into the lentiviral vector pSIN18.cPPT.hEF1_p. EGFP.WPRE producing the reporter enhanced green fluorescent protein (EGFP) using the XhoI and EcoRV restriction sites. The plasmids $\mathrm{pBS}-\mathrm{H} 1$ and the lentiviral vector pSIN18.cPPT.hEF1_p.EGFP.WPRE were kindly provided by Dr M. Gropp (Hadassah Human Embryonic Stem Cell Research Center, Goldyne Savad Institute of Gene Therapy, Hadassah University Medical Center, Jerusalem, Israel).

Transduction of INS-1E cells and generation of Txnip knockdown cells INS-1E cells were plated in six-well plates and grown overnight to approximately $70 \%$ confluence. The cell medium was exchanged for concentrated viruscontaining medium for $18-24 \mathrm{~h}$ and then replaced with fresh culture medium. Transduced INS-1E cells were plated at low density. EGFP-producing colonies were picked, replated and propagated to give a polyclonal cell line expressing the Txnip silencing cassette.

Quantitative real-time $R T-P C R$ RNA was extracted from INS-1E cells using Trireagent (Biolab, Jerusalem, Israel); samples of $1 \mu \mathrm{g}$ total RNA were reverse transcribed using Moloney murine leukaemia virus reverse transcriptase (Promega, Madison, WI, USA). Quantitative real-time RTPCR for Txnip was performed on a Prism 7000 Sequence Detection System using the TaqMan Gene Expression Assay (Applied Biosystems, Foster City, CA, USA). All samples were analysed in triplicate and corrected for the $18 \mathrm{~S}$ ribosomal subunit (Applied Biosystems) used as an internal control.

Transient transfection experiments INS-1E cells were plated in 24-well plates and grown overnight to approximately $70 \%$ confluence. Cells were co-transfected with a reporter construct encoding the human TXNIP promoter region 1,777 bp upstream of the ATG start codon (kindly provided by A. Shalev, University of Wisconsin-Madison, Madison, WI, USA) and pRL-TK control plasmid expressing the luciferase reporter gene (Promega). Transfection was performed in serum-free RPMI medium using Lipofectamine (Invitrogen, Philadelphia, PA, USA) according to the manufacturer's instructions. Six hours after transfection, the medium was replaced and transcriptional activity was assessed after overnight incubation in medium containing different glucose concentrations. Luciferase activity was determined using a luciferase assay kit (Promega).

Western blot analysis Expression of TXNIP protein and thioredoxin was studied by a standard western blot technique using monoclonal rabbit antibodies against TXNIP (MBL International, Woburn, MA, USA) and thioredoxin (kindly provided by Dr M. Chevion, Hebrew University, Jerusalem, Israel). Activation of insulin signalling was assessed by analysing the expression and serine 473 phosphorylation of protein kinase B (PKB)/Akt using polyclonal rabbit antibodies (Cell Signaling Technology, Beverly, MA, USA). Molecular activation of apoptosis was assessed by measurement of cleaved vs total caspase 3 using polyclonal goat anti-rabbit antibodies (Cell Signaling Technology). X-ray film densitometry was used for quantification (ImageMaster VDS-CL; Amersham Pharmacia Biotech, Little Chalfont, UK).

Insulin assay Immunoreactivity of $P$. obesus and rat (INS1E) insulin was determined using commercial human and rat RIA kits (Linco Research, St Charles, MI, USA). The routine intra-assay coefficient of variation was $4-6 \%$ and the interassay coefficient of variation was $6-10 \%$.

Apoptosis ELISA Cells were plated in 96-well plates and grown in RPMI 1640 medium containing $11.1 \mathrm{mmol} / 1$ glucose until they reached $70 \%$ confluence. The cells were then cultured at 11.1 or $27.8 \mathrm{mmol} / 1$ glucose for $48 \mathrm{~h}$. The cells were lysed and oligonucleosomes in the cytosol indicative of apoptosis-induced DNA degradation were quantified using the cell death ELISA ${ }^{\text {PLUS }}$ assay (Roche Diagnostics, Mannheim, Germany) according to the manufacturer's instructions.

Data presentation and statistical analysis Data are shown as mean \pm SEM. The statistical significance of differences between groups was determined by one-way ANOVA followed by the Newman-Keuls test using the InStat statistical program (Graphpad Software, San Diego, CA, USA). A paired-sample $t$ test was used when the difference between a reference (taken as 100\%) and the test was analysed. A $p$ value of less than 0.05 was considered significant.

\section{Results}

Glucose stimulates TXNIP protein production in P. obesus islets and INS-1E beta cells In islets of normoglycaemic $P$. obesus, TXNIP protein was not detected; however, 


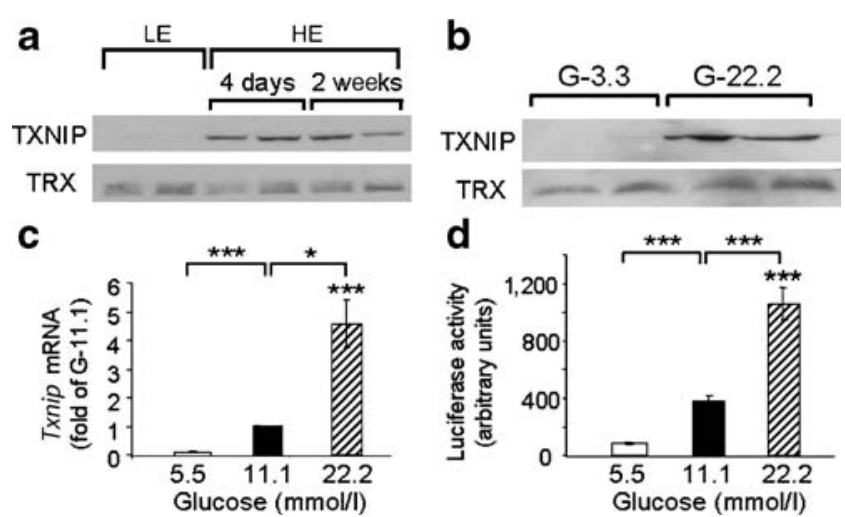

Fig. 1 Effects of hyperglycaemia on TXNIP protein production in vivo and in vitro. a TXNIP and thioredoxin (TRX) protein production in islets isolated from normoglycaemic $P$. obesus fed a low-energy (LE) diet and from diabetic animals fed a high-energy (HE) diet. TXNIP and thioredoxin were analysed by western blotting. b TXNIP and thioredoxin protein production in islets derived from normoglycaemic $P$. obesus after exposure to 3.3 and $22.2 \mathrm{mmol} / \mathrm{l}$ glucose for $48 \mathrm{~h}$. Effects of glucose on Txnip mRNA levels (c) and gene transcription (d). INS-1E cells were incubated in medium containing $5.5-22.2 \mathrm{mmol} / \mathrm{l}$ glucose for $24 \mathrm{~h}$ followed by quantitative real-time PCR for Txnip. All RNA samples were analysed in triplicate and corrected for the $18 \mathrm{~S}$ ribosomal subunit, which served as an internal control. Transcriptional activity was analysed after transient transfection with a reporter construct encoding the human TXNIP promoter region $1,777 \mathrm{bp}$ upstream of the ATG start codon. Results are mean \pm SEM. $* p<0.05, * * * p<0.001$ for the differences between the indicated groups and between 22.2 and $5.5 \mathrm{mmol} / 1$ glucose

development of hyperglycaemia after 4 days on a highenergy diet was associated with prominent induction of TXNIP, which was sustained at 2 weeks (Fig. 1a), while thioredoxin production was not modified. In vitro exposure of $P$. obesus islets to $22.2 \mathrm{mmol} / 1$ glucose for $48 \mathrm{~h}$ induced strong TXNIP protein production (Fig. 1b), indicating that hyperglycaemia accounts for the induction of TXNIP in diabetic animals. In accordance with previous studies, we found that glucose stimulated Txnip transcription and increased mRNA levels in INS-1E cells in a dosedependent manner (Fig. 1c, d); thus, glucose regulates TXNIP production at the level of transcription.

Insulin regulates TXNIP in beta cells The effect of the secreted insulin on TXNIP levels was studied in INS-1E beta cells using different insulin secretagogues and the $\mathrm{K}^{+}$-ATP channel opener diazoxide. INS-1E cells were cultured for $2 \mathrm{~h}$ at $11.1 \mathrm{mmol} / \mathrm{l}$ glucose without and with $500 \mathrm{nmol} / \mathrm{l}$ human insulin or different insulin secretagogues; the latter increased insulin secretion four- to fivefold (Fig. 2a). These measures resulted in a marked decrease in Txnip mRNA (Fig. 2b) and TXNIP protein levels (Fig. 2c). To confirm that the inhibition of TXNIP by insulin secretagogues is mediated by secreted insulin, INS-1E cells were treated with IBMX or the glucagon-like peptide 1 (GLP-1) analogue exendin 4 with and without diazoxide. Diazoxide prevented the stimulation of insulin secretion by IBMX and exendin 4 (Fig. 3a); this completely abolished the suppression of TXNIP by IBMX, but only partially affected the inhibition induced by exendin 4 (Fig. 3b). The latter observation indicates that additional mechanisms are involved in the regulation of TXNIP by the GLP-1 analogue.

Role of insulin secretion in nutrient regulation of TXNIP The role of insulin in the regulation of TXNIP by nutrients was studied in P. obesus islets and INS-1E beta cells exposed to high concentrations of glucose and/or palmitate. Overnight incubation of $P$. obesus islets with diazoxide completely abolished glucose-stimulated insulin secretion (Fig. 4a) while leading to enhancement of glucose-stimulated TXNIP protein levels (Fig. 4b). This suggests that insulin negatively regulates TXNIP protein in islets.

Short-term exposure to palmitate amplifies glucosestimulated insulin secretion in beta cells. To further study the effects of secreted insulin on TXNIP protein production,
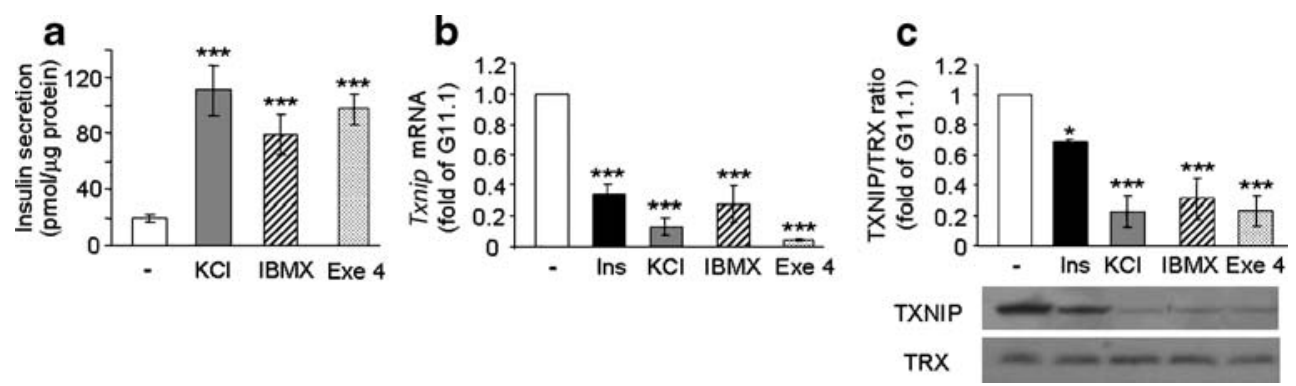

Fig. 2 Effects of insulin and insulin secretagogues on Txnip gene expression and protein levels. INS-1E cells were cultured overnight at $3.3 \mathrm{mmol} / 1$ glucose and then incubated for $2 \mathrm{~h}$ at $11.1 \mathrm{mmol} / 1$ glucose alone or with and without $500 \mathrm{nmol} / 1$ insulin (Ins), $40 \mathrm{mmol} / 1 \mathrm{KCl}$, $0.5 \mathrm{mmol} / 1 \mathrm{IBMX}$ or $100 \mathrm{nmol} / 1$ exendin 4 (Exe 4). Insulin secretion (a); Txnip mRNA (b); TXNIP protein levels (c). Cumulative insulin secretion into the medium was determined by RIA. Insulin concen- trations in medium at the end of the static incubations in the four treatment groups were as follows: untreated, $4.1 \pm 0.3 \mathrm{nmol} / 1 ; \mathrm{KCl}$, $21.7 \pm 3.2 \mathrm{nmol} / 1$; IBMX, $17.3 \pm 3.0 \mathrm{nmol} / \mathrm{l}$; exendin, $19.6 \pm 1.9 \mathrm{nmol} / \mathrm{l}$. TXNIP and thioredoxin (TRX) protein production was analysed by western blotting. TXNIP protein was normalised to TRX. Results are expressed as mean \pm SEM of three individual experiments. ${ }^{*} p<0.05$, $* * * p<0.001$ for indicated treatments compared with control 


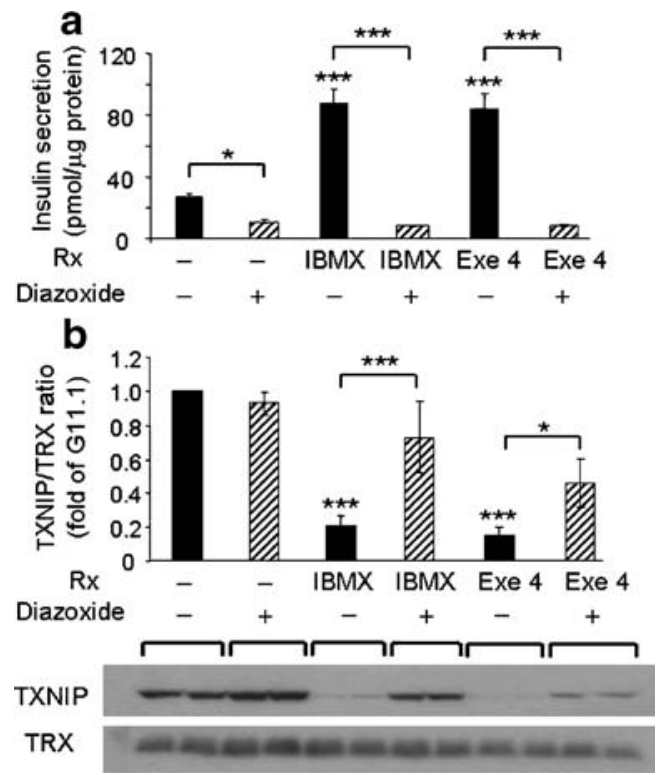

Fig. 3 Role of secreted insulin in TXNIP suppression by insulin secretagogues. INS-1E cells were cultured overnight at $3.3 \mathrm{mmol} / 1$ glucose and then incubated for $2 \mathrm{~h}$ at $11.1 \mathrm{mmol} / \mathrm{l}$ glucose and $0.5 \mathrm{mmol} / 1 \mathrm{IBMX}$ or $100 \mathrm{nmol} / 1$ exendin 4 (Exe 4) with and without $250 \mu \mathrm{mol} / 1$ diazoxide. a Insulin secretion. Insulin concentrations in medium at the end of the static incubations were as follows: untreated, $7.4 \pm 0.6 \mathrm{nmol} / 1$; diazoxide, $2.9 \pm 0.3 \mathrm{nmol} / 1$; IBMX, $21.8 \pm 2.3 \mathrm{nmol} / 1$; IBMX and diazoxide, $2.0 \pm 0.1 \mathrm{nmol} / \mathrm{l}$; exendin 4, $21.7 \pm 2.7 \mathrm{nmol} / \mathrm{l}$; exendin 4 and diazoxide, $2.3 \pm 0.2 \mathrm{nmol} / \mathrm{l}$. b TXNIP protein levels normalised to thioredoxin (TRX), shown with a representative gel. Results are expressed as mean \pm SEM of three individual experiments. $* p<0.05, * * * p<0.001$ for differences between indicated groups and untreated controls. Rx, treatment

INS-1E cells were stimulated for $2 \mathrm{~h}$ with 11.1 and $22.2 \mathrm{mmol} / 1$ glucose with and without $0.5 \mathrm{mmol} / 1$ palmitate in the presence and absence of diazoxide. As expected, treatment with glucose and palmitate amplified insulin

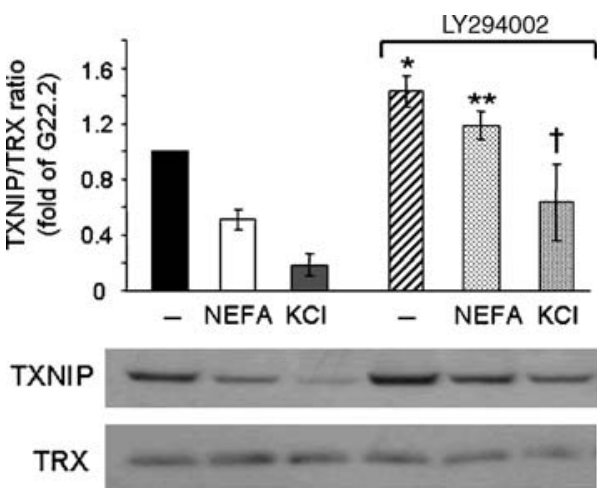

Fig. 5 Effect of PI3 kinase inhibition on TXNIP protein levels. INS$1 \mathrm{E}$ cells were cultured overnight at $3.3 \mathrm{mmol} / \mathrm{l}$ glucose and then incubated in medium containing $22.2 \mathrm{mmol} / 1$ glucose with and without $0.5 \mathrm{mmol} / \mathrm{l}$ palmitate or $40 \mathrm{mmol} / 1 \mathrm{KCl}$ and $20 \mu \mathrm{mol} / 1 \mathrm{LY} 294002$ for $2 \mathrm{~h}$. TXNIP and thioredoxin (TRX) protein were analysed by western blotting. A representative gel is shown in the lower panel. Quantification of TXNIP protein levels normalised to TRX is shown in the upper panel. Results are mean \pm SEM of four individual experiments. ${ }^{*} p<0.05$, ${ }^{* *} p<0.01,{ }^{\dagger} p=0.06$ for difference between treatment groups and matched controls

secretion, whereas diazoxide efficiently inhibited secretion (Fig. 4c). Glucose increased TXNIP protein in a concentration-dependent manner. Diazoxide increased TXNIP protein only modestly at 11.1 or $22.2 \mathrm{mmol} / 1$ glucose, indicating that glucose stimulation of TXNIP dominates over the inhibitory effect of insulin (Fig. 4d). The sixfold amplification of insulin secretion by palmitate resulted in a marked decrease in the TXNIP level, an effect that was prevented by diazoxide (Fig. 4d).

Pharmacological inhibition of PI3 kinase by LY294002 increased TXNIP protein levels in beta cells treated with glucose and palmitate or in response to non-nutrient stimulation of insulin secretion (KCl) (Fig. 5). Thus, a

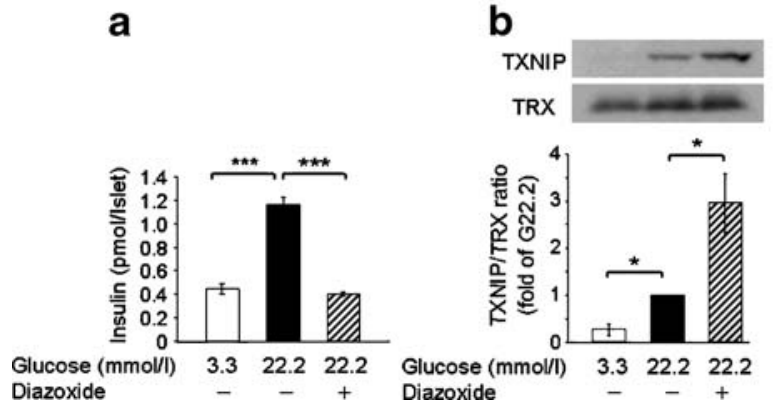

C

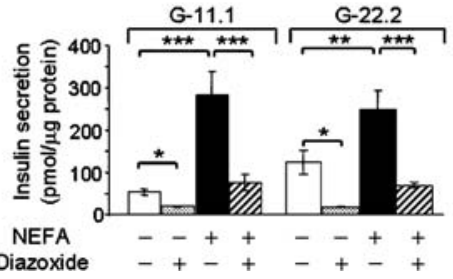

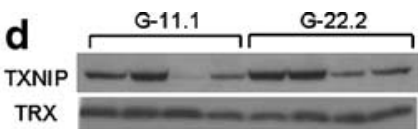

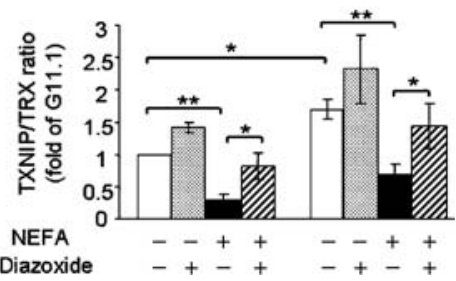

Fig. 4 Effect of nutrient-stimulated insulin secretion on TXNIP production in $P$. obesus islets and INS-1E cells. a, b $P$. obesus islets were incubated overnight in medium containing $3.3 \mathrm{mmol} / 1$ glucose or $22.2 \mathrm{mmol} / 1$ glucose with and without $250 \mu \mathrm{mol} / 1$ diazoxide. $\mathbf{c}, \mathbf{d}$ INS$1 \mathrm{E}$ cells were cultured overnight at $3.3 \mathrm{mmol} / 1$ glucose and then incubated at 11.1 and $22.2 \mathrm{mmol} / 1$ glucose in the presence and absence of $0.5 \mathrm{mmol} / \mathrm{l}$ palmitate and $250 \mu \mathrm{mol} / 1$ diazoxide for $2 \mathrm{~h}$. Insulin secretion is shown in a and c. Insulin concentrations in medium at the end of the static incubations of the INS-1E cells were as follows: untreated at $11.1 \mathrm{mmol} / 1$ glucose, $12.9 \pm 1.8 \mathrm{nmol} / \mathrm{l}$; diazoxide at
$11.1 \mathrm{mmol} / 1,4.9 \pm 0.2 \mathrm{nmol} / \mathrm{l}$; palmitate at $11.1 \mathrm{mmol} / 1$ glucose, $77.8 \pm$ $14.9 \mathrm{nmol} / \mathrm{l}$; palmitate and diazoxide at $11.1 \mathrm{mmol} / 1$ glucose, $20.1 \pm$ $4.9 \mathrm{nmol} / \mathrm{l}$; untreated at $22.2 \mathrm{mmol} / \mathrm{l}$ glucose, $30.1 \pm 6.9 \mathrm{nmol} / \mathrm{l}$; diazoxide at $22.2 \mathrm{mmol} / 1$ glucose, $4.4 \pm 0.2 \mathrm{nmol} / 1$; palmitate at $22.2 \mathrm{mmol} / \mathrm{l}$ glucose, $62.3 \pm 11.0 \mathrm{nmol} / \mathrm{l}$; palmitate and diazoxide at $22.2 \mathrm{mmol} / \mathrm{l}$ glucose, $16.5 \pm 1.5 \mathrm{nmol} / \mathrm{l}$. b, d TXNIP protein levels were normalised to thioredoxin (TRX). Results are mean \pm SEM of five individual experiments. ${ }^{*} p<0.05, * * p<0.01, * * * p<0.001$ for differences between indicated groups 
interference with insulin signalling at the level of PI3 kinase prevents the inhibition of TXNIP by insulin.

Nitric oxide is required for the effect of insulin on TXNIP Nitric oxide was shown to suppress TXNIP production in rat pulmonary artery muscle cells [18]. Moreover, NO promoted beta cell survival in response to insulin and IGF-1 [19]. Therefore, we studied the effects of modulating beta cell NO levels on insulin signal transduction and TXNIP protein levels.

Inhibition of NOS by L-NAME abolished PKB/Akt (Ser473) phosphorylation in INS-1E beta cells, whereas the NO donor GSNO increased it (Fig. 6a). The attenuation of insulin signalling by L-NAME increased TXNIP protein levels (Fig. 6b), whereas the NO donor
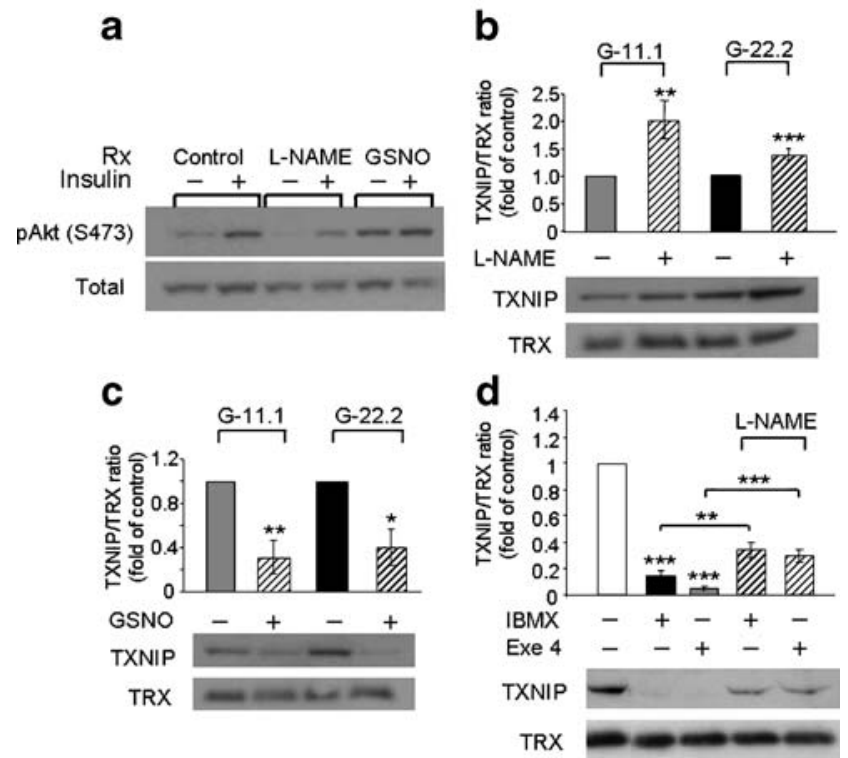

Fig. 6 Effects of NO generation and NO synthase inhibition on insulin signalling (a) and TXNIP protein levels (b-d). a INS-1E cells were incubated overnight in RPMI medium containing $3.3 \mathrm{mmol} /$ 1 glucose and $0.5 \%$ bovine serum albumin without serum and then treated with the NO donor GSNO $(100 \mu \mathrm{mol} / 1)$ or the NO synthase inhibitor L-NAME $(10 \mathrm{mmol} / \mathrm{l})$ for $2 \mathrm{~h}$. Cells were then stimulated with $500 \mathrm{nmol} / 1$ insulin for $15 \mathrm{~min}$. Activation of insulin signalling was assessed by measuring serine $473 \mathrm{PKB} / \mathrm{Akt}$ phosphorylation. Results were normalised to total $\mathrm{PKB} / \mathrm{Akt}$ protein expression. A gel representative of three individual experiments is shown. b INS-1E cells cultured at 11.1 and $22.2 \mathrm{mmol} / 1$ glucose were treated with and without $10 \mathrm{mmol} / 1 \mathrm{~L}-\mathrm{NAME}$ for $24 \mathrm{~h}$. c Cells cultured at 11.1 and $22.2 \mathrm{mmol} / \mathrm{l}$ glucose were incubated with and without $100 \mu \mathrm{mol} /$ 1 GSNO for $2 \mathrm{~h}$. d Cells were cultured overnight at $3.3 \mathrm{mmol} / \mathrm{l}$ glucose with and without $10 \mathrm{mmol} / \mathrm{L}-\mathrm{NAME}$ and then treated with $0.5 \mathrm{mmol} /$ 1 IBMX or $100 \mathrm{nmol} / \mathrm{l}$ exendin 4 (Exe 4) for $2 \mathrm{~h}$. TXNIP and thioredoxin (TRX) protein expression levels were analysed by western blotting. Representative gels and quantification of TXNIP protein expression normalised to TRX are shown. Results are expressed as mean \pm SEM of seven (b) and four (c, d) individual experiments. ${ }^{*} p<$ $0.05, * * p<0.01, * * * p<0.001$ for indicated groups compared with untreated controls. Rx, treatment

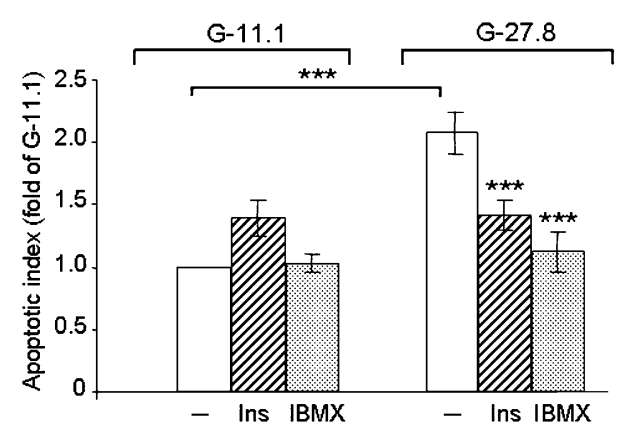

Fig. 7 Effects of insulin (Ins) and IBMX on glucose-induced beta cell apoptosis. INS-1E cells were incubated at 11.1 and $27.8 \mathrm{mmol} / 1$ glucose in serum-free medium with $500 \mathrm{nmol} / 1$ insulin or $0.5 \mathrm{mmol} / 1 \mathrm{IBMX}$ for $24 \mathrm{~h}$. Apoptosis was assessed using the apoptosis ELISA assay. $* * * p<0.001$ for difference between $27.8 \mathrm{mmol} / 1$ glucose and $11.1 \mathrm{mmol} / \mathrm{l}$ or the indicated groups

GSNO decreased TXNIP protein (Fig. 6c). Moreover, pretreatment of INS-1E cells with L-NAME attenuated the inhibition of TXNIP by the insulin secretagogues IBMX and exendin 4 (Fig. 6d).

Taken together, the direct relationship between cellular $\mathrm{NO}$ and insulin signal activation and the inhibitory effect of insulin on TXNIP suggest that NO suppresses TXNIP by stimulation of insulin signalling. Moreover, NO is required for insulin signal transduction in beta cells and for the inhibition of TXNIP by insulin secretagogues.

Insulin protects beta cells from glucose-induced apoptosis The effects of insulin on beta cell survival in response to hyperglycaemia were studied by incubating INS-1E cells at 11.1 and $27.8 \mathrm{mmol} / \mathrm{l}$ glucose with and without different concentrations of insulin or $0.5 \mathrm{mmol} / \mathrm{l}$ IBMX for $24 \mathrm{~h}$. Exposure to exogenous insulin or enhancement of insulin secretion by IBMX decreased beta cell apoptosis (Fig. 7).

Partial knockdown of Txnip prevents glucose-induced beta cell apoptosis Insulin decreased both TXNIP production and beta cell apoptosis. To confirm that insulin protects beta cells from glucose-induced apoptosis through inhibition of TXNIP, we partially knocked down Txnip in INS-1E cells, mimicking the effect of insulin. RNA interferencemediated Txnip knockdown decreased TXNIP protein levels to $50 \%$ of that in EGFP control cells (Fig. 8a, b). Culture of control cells at $27.8 \mathrm{mmol} / 1$ glucose for $48 \mathrm{~h}$ increased beta cell apoptosis two- to threefold. Partial Txnip knockdown completely prevented glucose-induced beta cell apoptosis (Fig. 8c, d).

TXNIP deficiency may prevent apoptosis through activation of PKB/Akt [14, 20]. Therefore, we studied whether partial Txnip knockdown increased PKB/Akt phosphorylation in beta cells. However, insulin-stimulated $\mathrm{PKB} / \mathrm{Akt}$ phosphorylation was not increased in TXNIP- 


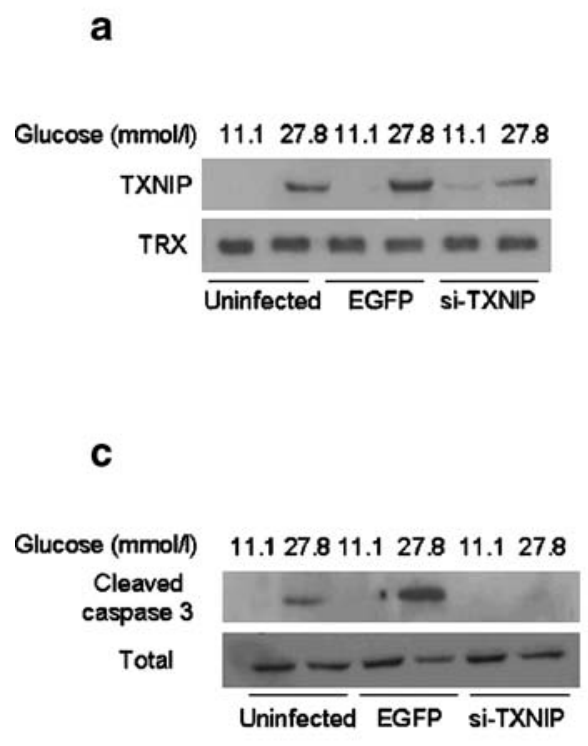

Fig. 8 Effects of RNA interference-mediated Txnip knockdown on glucose-induced beta cell apoptosis. INS-1E cells were either transduced with lentiviral vectors expressing EGFP and RNA interference oligos targeting Txnip (small interfering Txnip; si-TXNIP) or EGFP alone (EGFP), or remained uninfected. The cells were then incubated at 11.1 and $27.8 \mathrm{mmol} / \mathrm{l}$ glucose for $48 \mathrm{~h}$ followed by

deficient cells (see Electronic supplementary material, ESM Fig. 1), indicating that the antiapoptotic effect of TXNIP inhibition in our system is not mediated by $\mathrm{PKB} / \mathrm{Akt}$ signalling.

\section{Discussion}

The main finding of the present study is that insulin is a negative regulator of TXNIP in beta cells. Insulin and potent inducers of insulin secretion including membrane depolarisation, cAMP, NEFA and the GLP-1 agonist exendin 4 suppressed TXNIP production. The latter is in accordance with the results of Chen et al. [21], who also found that exendin 4 inhibits Txnip mRNA and protein levels in beta cells. Inhibition of insulin secretion or its signalling through PI3 kinase increased TXNIP levels, indicating that the effects of the different secretagogues on TXNIP levels are indeed mediated by insulin. Further support for the role of insulin as an inhibitor of TXNIP is provided by the observation that insulin downregulates TXNIP gene expression in human skeletal muscle in vivo [15]. Moreover, treatment of muscle insulin receptor knockout mice with insulin, while normalising blood glucose, failed to decrease TXNIP production in muscle $[15,22]$, indicating that the suppression of TXNIP by
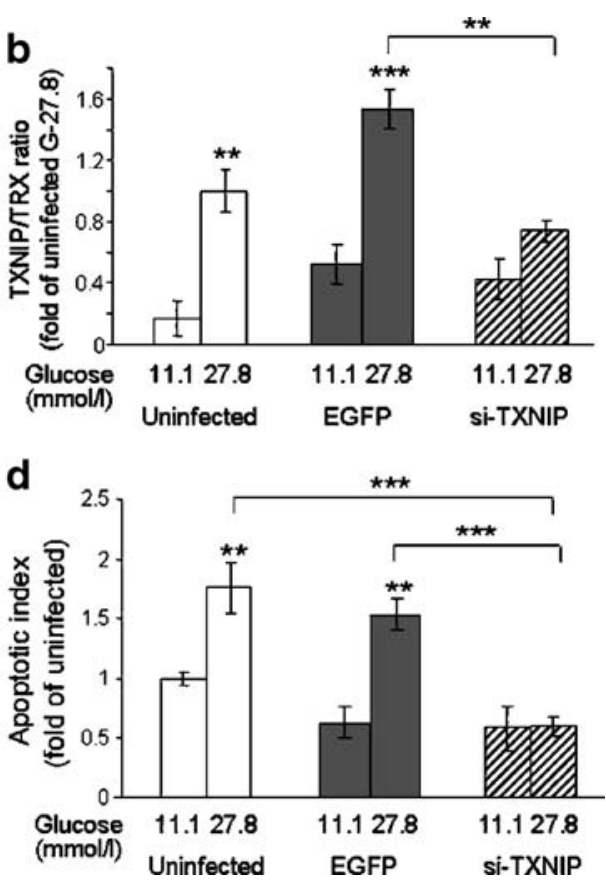

analysis for TXNIP protein levels $(\mathbf{a}, \mathbf{b})$ and apoptosis $(\mathbf{c}, \mathbf{d})$. a TXNIP protein production analysed by western blotting. b Quantification of TXNIP protein production normalised to thioredoxin (TRX). Apoptosis was assessed by (c) western blotting for cleaved caspase 3 and (d) using the apoptosis ELISA assay. ${ }^{* *} p<0.01,{ }^{* * *} p<0.001$ for indicated groups compared with untreated controls

insulin in vivo requires intact insulin signalling and is not simply secondary to decreased blood glucose.

Our findings show that PI3 kinase-PKB/Akt signalling is involved in the regulation of TXNIP by insulin in beta cells. Similarly, it has been shown that growth factors suppress TXNIP in vascular smooth muscle cells and in cerebellar neurons undergoing apoptosis through a PI3 kinase-dependent pathway [9, 23]. Interestingly, insulin signalling interacts with NO to regulate TXNIP. NO activates PKB/Akt and is required for its full activation by insulin. In addition, it is a potent repressor of TXNIP in beta cells (Fig. 6) and in rat pulmonary artery smooth muscle cells [18]. Taken together, these findings suggest that NO mediates the suppression of TXNIP by activation of insulin signalling.

The mechanisms underlying PI3 kinase-PKB/Aktmediated suppression of TXNIP are not known. The Txnip promoter contains a conserved binding site for the forkhead family of transcription factors. These factors are regulated by $\mathrm{PKB} / \mathrm{Akt}-$ mediated phosphorylation, leading to their nuclear exclusion and inactivation [24]. Recently, it has been reported that TXNIP is a direct target of the forkhead transcription factor FOXO1A [25]. Thus, PI3 kinase-PKB/Akt could regulate TXNIP through the FOXO family of transcription factors.

Lack of TXNIP was recently shown to increase PKB/ Akt phosphorylation by reducing the activity of phospha- 
tase and tensin homologue (PTEN) in muscle [20]. Thus, insulin inhibition of TXNIP generates a feed-forward loop that augments insulin signalling through $\mathrm{PKB} / \mathrm{Akt}$, hence increasing insulin sensitivity; this in turn may further reduce TXNIP levels. However, unlike the effects of TXNIP deficiency in muscle, partial Txnip knockdown did not enhance insulin signalling in beta cells, suggesting that in our system the protective effect of TXNIP inhibition is not mediated by $\mathrm{PKB} /$ Akt. Nevertheless, we cannot exclude the possibility that suppression of TXNIP to a greater extent than achieved here $(\sim 50 \%)$ could enhance insulin signal transduction also in beta cells. Moreover, it was recently shown that TXNIP deficiency prevented beta cell apoptosis in vivo, protecting the animals from hyperglycaemia and hypoinsulinaemia and thereby increasing $\mathrm{PKB} / \mathrm{Akt}$ signalling [14]. Therefore, enhanced insulin signalling may contribute to beta cell survival in TXNIPdeficient animals.

Glucose is the most potent stimulus for both TXNIP production and insulin secretion. The inverse effects of glucose and insulin on TXNIP production imply that stimulation of insulin secretion by glucose exerts a negative feedback loop that curtails the stimulation of TXNIP in response to hyperglycaemia. This may serve as an important compensatory mechanism that protects beta cells from oxidative damage and apoptosis under prolonged hyperglycaemia. This contention is supported by the finding in our study that even partial Txnip knockdown, similar to the reduction obtained by insulin or insulin secretagogues, was sufficient to completely prevent glucose-induced beta cell apoptosis. Moreover, our finding that both IBMX and exendin 4 efficiently decreased TXNIP production through insulin secretion suggests that insulin inhibition of TXNIP is an important mediator also of the well-established GLP-1 and cAMP protection of beta cells. Indeed, treatment of beta cells incubated under glucotoxic conditions with insulin or IBMX reduced beta cell apoptosis, further emphasising the physiological importance of TXNIP inhibition by insulin.

Palmitate is toxic to beta cells through multiple, incompletely understood mechanisms [3, 4]. Intriguingly, palmitate decreased TXNIP production, rather than increasing it. Thus, suppression of TXNIP by palmitate might constitute an adaptive mechanism that reduces beta cell damage under conditions of glucolipotoxicity. We expected that inhibition of insulin secretion under these conditions, by increasing TXNIP production would amplify beta cell apoptosis. However, diazoxide treatment of INS-1E cells cultured at high glucose with and without palmitate did not increase beta cell apoptosis (not shown). This probably results from the smaller effect of secreted insulin on TXNIP production compared with the strong stimulatory effect of high glucose. Moreover, diazoxide may protect beta cells from the toxic effects of elevated glucose and NEFA by reducing calcium flux and endoplasmic reticulum stress [26]. Therefore, diazoxide may have beneficial effects, which counteract its effects on TXNIP production.

Beta cell dysfunction has a central role in the development and progression of diabetes [27, 28]. It is well established that insulin secretion is impaired in type 2 diabetes [1, 29-31]. In addition, it was suggested that insulin signal transduction is perturbed in diabetic beta cells [32]. Thus, it is possible that increased TXNIP production in beta cells due to hyperglycaemia and insulin deficiency may have a central role in the pathophysiology of type 2 diabetes. According to this paradigm, hyperglycaemia generates a vicious cycle by inducing TXNIP, which in turn causes beta cell apoptosis and promotes insulin deficiency. The latter is expected to augment TXNIP production, leading to a further increase in beta cell apoptosis and consequently decreased beta cell mass and function, with exacerbation of hyperglycaemia.

Recent studies underscore the importance of TXNIP in glucose metabolism in the liver, fat and muscle, in addition to its involvement in the regulation of oxidative stress [15, 33, 34]. Thus, Txnip-null mice are hypoglycaemic and exhibit decreased hepatic glucose production [33]. In addition, TXNIP functions as a negative regulator of glucose uptake in adipocytes and muscle, suggesting that insulin-mediated glucose uptake in peripheral tissues depends on the inhibition of TXNIP [15]. Moreover, TXNIP production is consistently elevated in the muscles of prediabetic and diabetic individuals [15]; therefore, TXNIP might be an important cause of insulin resistance in type 2 diabetes. Taken together, the deleterious effects of TXNIP on peripheral insulin sensitivity and on beta cell survival indicate that TXNIP is an important pathogenic factor in type 2 diabetes, linking insulin resistance and beta cell dysfunction.

In summary, glucose and insulin coordinately regulate TXNIP in beta cells. Glucose is the most potent physiological inducer of TXNIP, whereas secreted insulin creates a balance by restricting its production. Under conditions of hyperglycaemia these events are amplified; the inhibition of TXNIP by elevated insulin concentrations should be regarded as a compensatory mechanism for limiting the cellular stress induced by prolonged hyperglycaemia. In type 2 diabetes, insulin deficiency may augment TXNIP levels, leading to exacerbation of both beta cell dysfunction and insulin resistance, with severe hyperglycaemia as a result. This may have important implications for the treatment of type 2 diabetes. Inhibition of TXNIP in beta cells exposed to chronic hyperglycaemia may protect them from oxidative stress and apoptosis; thus TXNIP can become a novel therapeutic target in diabetes. 
Acknowledgements This study was supported by grants from Diab R\&D, Paris, and the Israel Science foundation (G. Leibowitz and N. Kaiser).

Duality of interest The authors declare that there is no duality of interest associated with this manuscript.

\section{References}

1. Prentki M, Nolan CJ (2006) Islet beta cell failure in type 2 diabetes. J Clin Invest 116:1802-1812

2. Kaiser N, Leibowitz G, Nesher R (2003) Glucotoxicity and betacell failure in type 2 diabetes mellitus. J Pediatr Endocrinol Metab 16:5-22

3. Poitout V, Robertson RP (2002) Minireview: secondary $\beta$-cell failure in type 2 diabetes - a convergence of glucotoxicity and lipotoxicity. Endocrinology 143:339-342

4. Robertson RP, Harmon J, Tran PO, Poitout V (2004) Beta-cell glucose toxicity, lipotoxicity, and chronic oxidative stress in type 2 diabetes. Diabetes 53(Suppl 1):S119-S124

5. Ivarsson R, Quintens R, Dejonghe S et al (2005) Redox control of exocytosis: regulatory role of NADPH, thioredoxin, and glutaredoxin. Diabetes 54:2132-2142

6. Yoshioka J, Schreiter ER, Lee RT (2006) Role of thioredoxin in cell growth through interactions with signaling molecules. Antioxid Redox Signal 8:2143-2151

7. Patwari P, Higgins LJ, Chutkow WA, Yoshioka J, Lee RT (2006) The interaction of thioredoxin with Txnip. Evidence for formation of a mixed disulfide by disulfide exchange. J Biol Chem 281:21884-21891

8. Minn AH, Hafele C, Shalev A (2005) Thioredoxin-interacting protein is stimulated by glucose through a carbohydrate response element and induces beta-cell apoptosis. Endocrinology 146:2397-2405

9. Schulze PC, Yoshioka J, Takahashi T, He Z, King GL, Lee RT (2004) Hyperglycemia promotes oxidative stress through inhibition of thioredoxin function by thioredoxin-interacting protein. J Biol Chem 279:30369-30374

10. Qi W, Chen X, Gilbert RE et al (2007) High glucose-induced thioredoxin-interacting protein in renal proximal tubule cells is independent of transforming growth factor-beta1. Am J Pathol 171:744-754

11. Turturro F, Friday E, Welbourne T (2007) Hyperglycemia regulates thioredoxin-ROS activity through induction of thioredoxin-interacting protein (TXNIP) in metastatic breast cancerderived cells MDA-MB-231. BMC Cancer 7:96

12. Minn AH, Hafele C, Shalev A (2005) Thioredoxin-interacting protein is stimulated by glucose through a carbohydrate response element and induces beta-cell apoptosis. Endocrinology 146:2397-2495

13. Chen J, Saxena G, Mungrue IN, Lusis AJ, Shalev A (2008) Thioredoxin-interacting protein: a critical link between glucose toxicity and beta cell apoptosis. Diabetes 57:938-944

14. Chen J, Hui ST, Couto FM et al (2008) Thioredoxin-interacting protein deficiency induces $\mathrm{Akt} / \mathrm{Bcl}-\mathrm{xL}$ signaling and pancreatic beta-cell mass and protects against diabetes. FASEB J 22:35813594

15. Parikh H, Carlsson E, Chutkow WA et al (2007) TXNIP regulates peripheral glucose metabolism in humans. PLoS Med 4:e158
16. Nesher R, Gross DJ, Donath MY, Cerasi E, Kaiser N (1999) Interaction between genetic and dietary factors determines betacell function in Psammomys obesus, an animal model of type 2 diabetes. Diabetes 48:731-737

17. Kaiser N, Corcos AP, Tur-Sinai A, Ariav Y, Cerasi E (1988) Monolayer culture of adult rat pancreatic islets on extracellular matrix: long term maintenance of differentiated B cell function. Endocrinology 123:834-840

18. Schulze PC, Liu H, Choe E et al (2006) Nitric oxide-dependent suppression of thioredoxin-interacting protein expression enhances thioredoxin activity. Arterioscler Thromb Vasc Biol 26:26662672

19. Cahuana GM, Tejedo JR, Hmadcha A et al (2008) Nitric oxide mediates the survival action of IGF-1 and insulin in pancreatic beta cells. Cell Signal 20:301-310

20. Hui ST, Andres AM, Miller AK et al (2008) Txnip balances metabolic and growth signaling via PTEN disulfide reduction. Proc Natl Acad Sci U S A 105:3921-3926

21. Chen J, Couto FM, Minn AH, Shalev A (2006) Exenatide inhibits beta-cell apoptosis by decreasing thioredoxin-interacting protein. Biochem Biophys Res Commun 346:1067-1074

22. Yechoor VK, Patti ME, Ueki K et al (2004) Distinct pathways of insulin-regulated versus diabetes-regulated gene expression: an in vivo analysis in MIRKO mice. Proc Natl Acad Sci U S A 101:16525-16530

23. Saitoh T, Tanaka S, Koike T (2001) Rapid induction and $\mathrm{Ca}(2+)$ influx-mediated suppression of vitamin D3 up-regulated protein 1 (VDUP1) mRNA in cerebellar granule neurons undergoing apoptosis. J Neurochem 78:1267-1276

24. Matsumoto M, Accili D (2005) All roads lead to FoxO. Cell Metab 1:215-216

25. de Candia P, Blekhman R, Chabot AE, Oshlack A, Gilad Y (2008) A combination of genomic approaches reveals the role of FOXO1a in regulating an oxidative stress response pathway. PLoS ONE 3:e1670

26. Sargsyan E, Ortsater H, Thorn K, Bergsten P (2008) Diazoxideinduced beta-cell rest reduces endoplasmic reticulum stress in lipotoxic beta-cells. J Endocrinol 199:41-50

27. Weyer C, Bogardus C, Mott DM, Pratley RE (1999) The natural history of insulin secretory dysfunction and insulin resistance in the pathogenesis of type 2 diabetes mellitus. J Clin Invest 104:787-794

28. Cerasi E, Boitard C, Efendic S, Ferrannini E, Henquin JC, Steiner DF (2001) The islet in type 2 diabetes: back to center stage. Diabetes 50(Suppl 1):S1-S3

29. Nesher R, Della Casa L, Litvin Y et al (1987) Insulin deficiency and insulin resistance in type 2 (non-insulin-dependent) diabetes: quantitative contributions of pancreatic and peripheral responses to glucose homeostasis. Eur J Clin Invest 17:266-274

30. Kahn SE (2000) The importance of the $\beta$-cell in the pathogenesis of type 2 diabetes mellitus. Am J Med 198:2S-8S

31. Poitout V, Robertson RP (2007) Glucolipotoxicity: fuel excess and beta-cell dysfunction. Endocr Rev 29:351-366

32. Gunton JE, Kulkarni RN, Yim S et al (2005) Loss of ARNT/ HIF1beta mediates altered gene expression and pancreatic-islet dysfunction in human type 2 diabetes. Cell 122:337-349

33. Chutkow WA, Patwari P, Yoshioka J, Lee RT (2008) Thioredoxininteracting protein (Txnip) is a critical regulator of hepatic glucose production. J Biol Chem 283:2397-2406

34. Yoshioka J, Imahashi K, Gabel SA et al (2007) Targeted deletion of thioredoxin-interacting protein regulates cardiac dysfunction in response to pressure overload. Circ Res 101:1328-1338 